\title{
Maximizing Performance of Plant Growth Regulators by Improving Spray Application
}

\author{
Martin J. Bukovac
}

ADDITIONAL INDEX wORDs. additives, adjuvants, atomization, delivery, deposit formation, droplet, impaction, retention, surfactants

SUMMARY. The importance of spray application and the role of spray additives are reviewed in reference to increasing the effectiveness of plant growth regulators (PGR). The spray application process is composed of a number of interrelated components, from formulation of the active ingredient into a sprayable, bioactive solution (emulsion/suspension), to atomization, delivery, retention, and penetration into the plant tissue. Each of these events is critical to performance of the PGR. Also, each can be affected by spray additives, particularly adjuvants, which may be incorporated in the formulation of the active ingredient or added to the spray mixture. The role of the individual components and effects of spray adjuvants, particularly surfactants and fertilizer adjuvants, on the component processes are discussed.

$\mathrm{P}$ lant growth regulators are unique chemicals that can regulate physiological processes that often cannot be effectively controlled by other cultural practices. They are generally effective in low concentrations (dose), have a narrow optimum concentration-response range and must be absorbed by the plant tissue (commonly leaves) to induce the desired biological response. In commercial horticulture they are most frequently applied as foliar sprays using water as the carrier solvent. Nonuniform distribution of the prescribed dose over the intended target leads to poor and inconsistent performance, and may result in overdosing of either a portion or the entire target. Thus, the performance of even the most active and effectively formulated PGR under the best environmental and plant cultural conditions will be determined primarily by the quality of the spray application practice.

Spray application of foliar-applied PGR, in the broadest sense, is dependent on and involves a broad range of interacting factors/events, namely: 1) effectiveness of the application equipment; 2) chemical/ physical characteristics and formulation of the active ingredient (a.i.) into an active, sprayable form; 3 ) atomization of the spray solution/ emulsion/suspension; 4) delivery of the spray cloud uniformly over the intended target; 5 ) spray droplet: plant surface interaction, leading to retention, droplet drying, and a.i. residue formation; 6) penetration and transport of the a.i. to the active site; 7 ) environmental factors, mainly temperature and relative humidity $(\mathrm{RH})$, prior to, during, and immediately following spray application, as well as during the presence of functional a.i. deposits; and 8) plant condition, particularly foliage, free from stress induced by environment, insects, diseases, or inadequate nutrition.

Department of Horticulture, Michigan State University, East Lansing, MI 48824-1325.

Original studies reported herein were supported by the Michigan Agricultural Experiment Station and the Agricultural Research Service, U.S. Department of Agriculture (SCA 58-3607-0-129). The author is indebted to R.G. Fader, C. Zavalloni, P. Sabbatini, and G. Sorrenti, Michigan State University, for technical assistance; D.L. Reichard, H.J. Retzer, R.D. Brazee, and J.A. Cooper, USDA Agricultural Research Service, for assistance with droplet measurements; and R.E. Whitmoyer, Electron Microscope Laboratory, Ohio State University, Wooster, for electron imaging. 
I will focus in my presentation on those components of the spray application process from atomization of the spray solution through droplet drying, and on the role of the subsequent a.i. deposit in PGR performance. Although application equipment is a critical factor, it is not within the scope of this workshop other than to illustrate some inherent limitations. Formulation and effects of the environment on PGR performance will be covered by other speakers.

\section{Atomization}

Atomization is the conversion of the spray liquid into a cloud of droplets. Most orchard sprayers atomize the liquid using nozzles forming ligaments by forcing the spray liquid through an orifice by high pressure, or by high velocity air after passing the spray liquid through a porous tube/ cylinder or over a preformed plate or disk (Matthews, 1999). Other nozzle systems (air inclusion, electrostatic, rotary sleeve, spinning disk) have been used but, for various reasons, have not been extensively adopted.

The droplet size population produced by most orchard spray nozzles varies from $<100-\mu \mathrm{m}$ to $>500-\mu \mathrm{m}$ diameter (Reichard et al., 1977). The droplet spectrum can be characterized by several parameters based on number, volume, and surface area (Ranz, 1956). However, the volume median diameter [VMD (i.e., where $50 \%$ of the spray volume is below and $50 \%$ above a given droplet diameter)] is most commonly used (Fig. 1). In most droplet spectra there are a large number of small droplets, but they represent a small percentage of the total spray volume. They contribute little to delivery of the PGR dose, but significantly to spray drift.

Most studies of droplet size distribution within the spray cloud have been performed using mostly water or simple solutions under static conditions. Such data are useful in documenting effects of nozzle and sprayer factors on droplet size distribution, but may not be representative of PGR sprays under field conditions. Data are needed on atomization of complex solutions (emulsions, suspensions, etc.), effects of droplet size distribution on spray delivery and retention and on performance of the a.i. under orchard conditions (Bukovac et al., 2002; Butler et al., 1997).
Detailed studies on absorption and transport of 2,4-dichlorophenoxyacetic acid $(2,4-\mathrm{D})$ and daminozide applied to field bean (Vicia faba) in formulated monosize droplet sprays $(50-500 \mu \mathrm{m})$ showed that at constant dose the efficiency of uptake (percent) was not related to droplet size or number, leaf coverage, concentration of the a.i., or application volume (Stevens and Bukovac, 1987). Similar results were obtained with gibberellic acid $\left(\mathrm{GA}_{3}\right)$ and numerous herbicides (Knoche, 1994a; Knoche et al., 2000).

Such data are particularly important, since growers routinely adjust flow rate to deliver the desired spray volume per tree or per acre, to accommodate difference in tree size, training systems, seasonal changes in foliation, canopy density, etc. As flow rate through the nozzle is changed, the spray droplet size distribution is also altered (Bukovac et al., 2002). This may pose a particular problem when using sprayers that atomize the spray solution with high velocity air. For example, droplet size distribution for a sprayer (Kinkelder; Marwald Ltd., Burlington, Ont., Canada) using air shear nozzles shifted significantly to larger droplets with an increase in flow rate (linear regression:
$\left.\mathrm{Y}_{\mathrm{VMD}}=165.40+2.92 x, \mathrm{r}=0.84^{* *}\right)$ and to smaller droplets with an increase in air velocity $\left(\mathrm{Y}_{\mathrm{VMD}}=368.91-66 x\right.$, $\left.\mathrm{r}=0.98^{* *}\right)$. Such changes in the spray droplet size pattern for any given volume may influence spray penetration into the canopy, retention and coverage. Further, pesticide manufacturers' recommendations often provide for delivering a suggested dose in a range of carrier volumes per unit area (Wise et al., 2004). In both situations, the spray droplet spectrum is altered as flow rate is adjusted. How does this affect PGR performance? Air velocity is generally not a problem unless it cannot be held constant in the sprayer system, which may occur in power take-off driven sprayers on uneven terrain.

\section{Delivery of the spray cloud}

Uniform and efficient delivery of the prescribed dose to fruit trees is difficult to achieve because of sprayer limitations and variation in planting systems, tree size and form and seasonal changes in canopy density and surface foliage characteristics (Bukovac et al., 2002; Kaul et al., 1996). The primary elements of spray delivery that may affect PGR performance are: 1) sprayer characteristics [e.g., air volume and

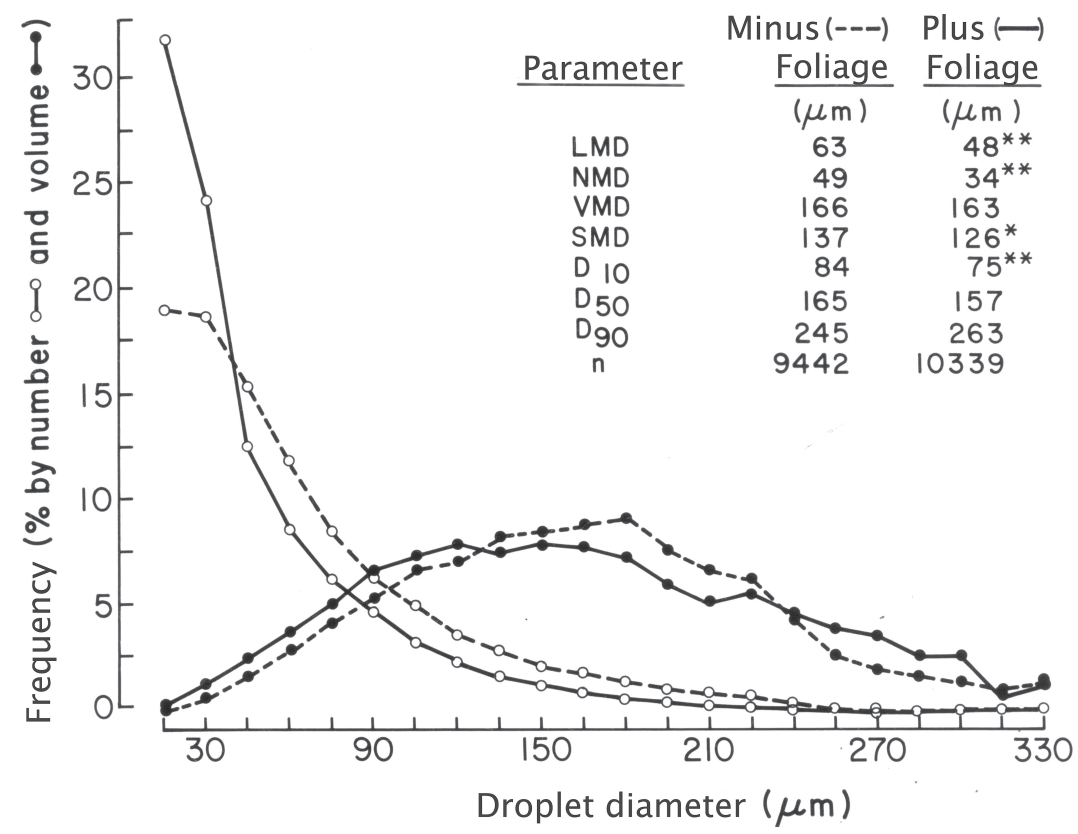

Fig. 1. Spray droplet size spectra, based on number and volume of spray in designated size classes, produced by a Kinkelder (3P-50) low volume orchard sprayer. Measurements were made at the periphery (dash line) and at $1 \mathrm{~m}(3.3$ $\mathrm{ft}$ ) in the canopy (solid line) of an apple tree with an optical array spectrometer probe. $\mathrm{LMD}=$ linear median diameter; $\mathrm{NMD}=$ number median diameter; VMD $=$ volume median diameter; $S M D=$ surface area median diameter; $\mathrm{D}_{10}, \mathrm{D}_{50}$, and $\mathrm{D}_{90}$ values represent the percentage of spray volume below the designated droplet diameter; $\mathbf{n}=$ number of droplets measured. 
velocity, nozzle type, fan type and location, and type of air delivery (turbulent or laminar)]; 2) tree characteristics (e.g., size, form, canopy structure, density, and wettability); 3) carrier volume (e.g., high vs. low volume); and 4) spray droplet size spectra.

In most orchard sprayers, axial fans are used to deliver the carrier air from essentially a point source, making it difficult to cover targets in the form of fruit trees. Further, orchard sprayers have generally been designed for multiple crop protection uses for only a generalized fruit tree form and thus it is difficult to match the spraying system to the unique requirements for a PGR. Other spraying systems are available (cross-flow fan, towers of varying designs, tunnel sprayers), but all have inherent limitations and have not been widely adopted. Air volume and velocity play a dominant role in delivery of the spray cloud. Generally, high volume, low velocity air flow provides for greatest spray penetration of the canopy (Randall, 1971).

Tree form and spray volume are two common factors affecting the uniformity of spray coverage. We evaluated spray deposition, using ethephon (2-chloroethylphosphonic acid) as a tracer, from a low volume sprayer (Kinkelder 3-P-50) at 102.9 to 411.6 $\mathrm{L} \cdot \mathrm{ha}^{-1}$ (11 to $44 \mathrm{gal} / \mathrm{acre}$ ) on young peach (Prunus persica) trees trained to either a hedge $\sim 2 \mathrm{~m}$ wide $\times \sim 3.4 \mathrm{~m}$ high $(6.6 \times 11 \mathrm{ft})$ or an open center $\sim 4.3 \mathrm{~m}$ wide $\times \sim 3 \mathrm{~m}$ high $(14 \times 9.8$ $\mathrm{ft})$. Aluminum targets were positioned vertically at the periphery [ $1 \mathrm{~m}(3.3$ $\mathrm{ft}$ ) from spray head] of the canopy 1 , 2 , and $3 \mathrm{~m}$ aboveground $(\mathrm{P} 1, \mathrm{P} 2, \mathrm{P} 3)$ and in the center $(\mathrm{Cl}, \mathrm{C} 2, \mathrm{C} 3)$ of the canopy ( $2 \mathrm{~m}$ from spray head). Spray deposition (microliters per square centimeter) for both tree training systems was greatest at the periphery on the lower tree quadrant next to the spray lane (Pl). Significantly less spray was deposited in the tops (C3) and in the center of the canopy $(\mathrm{Cl}, \mathrm{C} 2)$. The periphery was oversprayed by several fold $(2-5 x)$ compared to the interior of the canopy $(\mathrm{Pl} / \mathrm{C} 2)$ of the open-center trained trees. When spray volume was increased 102.9 to $411.6 \mathrm{~L} \cdot \mathrm{ha}^{-1}$, there was a corresponding linear increase in deposition for all positions; however, the increase in deposition on the lower periphery $(\mathrm{Pl})$ was greater than that in the tops of trees (C3) and both were greater than in the center (C2) of the canopy for both training systems. This lack of uniform spray distribution over the target is not unique for this study, but has also been observed for other orchard sprayers and tree training systems (Byers et al., 1989; Cross et al., 2001; Hogmire et al., 1991, 1992). Cross et al. (2001) reported an interesting finding that may have practical implications: deposition on fruitlets was consistently greater for low than for high flow rates.

The effects of changes in spray droplet spectra on deposition are not well defined. Generally, small droplets are difficult to deliver to the tree because of the low droplet mass; thus, they are subject to air currents, tend to drift, and fail to impinge on smooth, waxy leaf surfaces.

\section{Current concept of dose expression is unrealistic and misleading}

The current practice of recommending a constant dose per unit ground area occupied by the target trees is not only inconsistent with intended goals of effective pesticide application, but ignores the quantity and quality of the target and the biological requirement that PGR must be absorbed by the plant tissue before a response can be induced. Traditionally the dose : response relationship in developing horticultural uses for PGR has been based on conditions where spray volume is not limiting, i.e., full target retention volume (spray to runoff), and coverage is complete and uniform. Transfer of such data to crop use recommendations usually relies on a given concentration applied as a dilute (high volume) spray where the above conditions are satisfied. Growers recognize that for most PGRs an optimum response is obtained by dilute application. However, for a number of practical and economic reasons, dilute spraying is being (has been) replaced with lower (low volume) than full tree retention volume. As carrier volume is progressively reduced, spray volume eventually becomes limiting because of inadequate coverage and uniformity, a.i. penetration, and often phytotoxicity.

A critical factor in relating dose to performance under low volume application is to have a reliable measure of the full retention volume for the target. In high volume spraying this is not critical in determining performance, assuming that the a.i. concentration is correct, since any additional spray applied will run off, but has important economic and ecological implications. In order to deliver a dose equivalent to high volume application, using a low volume spray, one must have an accurate measure (estimate) of the full canopy retention value to establish the appropriate concentration needed for the low volume spray. A further complicating factor is that the appropriate concentration of a PGR applied as low volume spray may not be linearly related to the corresponding decrease in carrier volume.

Estimates of the full retention value for a given crop and planting system vary widely. Numerous factors that vary and interact make it difficult to obtain accurate estimates. For example, composition of the spray solution (e.g., spray additives) may markedly alter spray surface tension and thus retention. Spray equipment characteristics and dramatic changes in surface area and wettability of the foliage and fruit surfaces during the growing season may all affect spray retention (Bukovac et al., 1979; Hall et al., 1997). Numerous attempts have been made over the past 40 years to develop realistic expressions of dose for tree crops in different planting systems. One of the earliest attempts was made by Morgan and coworkers at Long Ashton Research Station (Morgan, 1964). Here the trees were viewed as a single continuous wall and they assumed the application of a constant amount of a.i. per unit area of the wall (i.e., tree height $\times$ length of row). Later, Byers et al. (1971) made a significant improvement that has been adopted extensively in the fruit industry. They introduced the Tree Row Volume model that takes into account the volume the tree occupies. One assumes in this model that the amount of a.i. applied is constant per unit volume of tree per length of tree row. Neither of these two models takes into consideration target density or changing surface characteristics affecting spray deposition and retention.

Further studies focused on tree size and canopy structure (Byers et al., 1984; Travis et al., 1987). Small ( 3 $\mathrm{m}$ high $)$ and medium $[\sim 4 \mathrm{~m}(13.1 \mathrm{ft})$ high] size 'Golden Delicious' apple (Malus $\times$ sylvestris var. domestica) trees trained to a modified central leader 
were pruned to three canopy density levels (low, medium, high) that were similar to trees in commercial orchards (Travis et al., 1987). In general, the amount and uniformity of deposit and canopy penetration were inversely related to canopy density. Adjusting tree row volume values using an empirically derived factor for canopy density tended to further minimize deposit variation (Sutton and Unrath, 1984).

Recent studies by Walklate et al. (2002) make significant additional contributions by introducing the element of tree structure. They found that tree area density was the tree structure parameter that best correlated with pesticide dose for apple orchard spraying. The area density was determined using data obtained with a light detection and ranging (LIDAR) system, which essentially scanned the target trees using a range of optical trajectories that simulated spray droplets passing through the canopy after being emitted from an axial fan sprayer. The LIDAR system is not currently convenient for general use. However, scans of trees in representative model planting systems might be made and conveyed to growers through consultants and outreach programs. See the excellent comparison of models and discussion in Walklate et al. (2002)

Even with these most significant advances, two additional elements affecting deposition and retention must be considered, namely, spray solution composition and target surface retention characteristics. Formulated a.i. and spray additives may alter surface tension and, to a lesser extent, viscosity of the spray, both affecting droplet capture and spray retention. Target surface chemistry and fine structure determine droplet reflection and surface wettability, and thus spray retention (Bukovac et al., 1979).

\section{Spray droplet : plant surface interaction}

Physicochemical characteristics of the spray solution (primarily surface tension and viscosity), dynamics of droplet impaction (mass, velocity, angle of incidence, charge) and fine structure (micro-roughness) and chemistry (polarity of functional groups) at the plant surface are the major factors that determine the degree of interaction between impacting spray droplets and the plant surface (Brunskill, 1956;
Bukovac et al., 1995; Furmidge, 1962; Hartley and Burnskill, 1958; Spillman, 1984; Wirth et al., 1991).

IMPACTION/REFLECTION/RETENTION. Droplet impaction leads to reflection or retention. Reflection represents a loss of the a.i. for the nonretained dose is not available for penetration. Further, the reflected droplets can contribute to spray drift and off-target contamination.

Retention is perhaps the most defining event in the PGR spraying process, for it determines the dose available for penetration. For any given spray solution and plant surface, an impacting droplet with a given kinetic energy will deform (spread out, flatten) to some maximum, then retract toward its original form (Fig. 2). If the kinetic energy exceeds a critical value, the deformed droplet will retract completely, become extended perpendicular to the target surface, and then leave that surface. Depending on the remaining energy, such droplets may be lost completely, or may impact on another site where the process is repeated or the droplet may be retained. These events occur very rapidly. The time from first droplet contact to leaving the target surface is generally less than $1 \mathrm{~ms}$ (Bukovac et al., 2002; Reichard et al., 1998). Droplets with less than some critical energy level will impact, deform, and retract to less than their original form. This process will be repeated some number of times (oscillate) until an equilibrium state is achieved. Such droplets are retained, spread out and dry, providing the PGR dose for absorption.

DROPLET DRYING AND A.I. DEPOSIT (RESIDUE) FORMATION. Droplet drying is sensitive to composition of the spray solution (spray additives), droplet size, target surface wettability (roughness), and environmental factors (temperature, humidity). Rapid drying, particularly of small droplets in low volume application, may reduce spreading and penetration. However, it appears that the higher a.i. concentration in the spray solution compensates by providing a greater driving force for penetration (Bukovac et al., 2002).

Immediately after retention the carrier solvent and volatile components (if present) begin to evaporate and the a.i. precipitates out as a droplet deposit (residue). The deposits vary in size, physical form, and consistency (Falk, 1994). The a.i. may be distributed uniformly over the original droplet/ plant surface interface or as masses of various sizes over veins, guard and accessory cells of stomata, damaged areas, around the base of trichromes, or other specialized structures (Fig. 3). These areas appear to be more easily wetted and may serve as preferential sites for
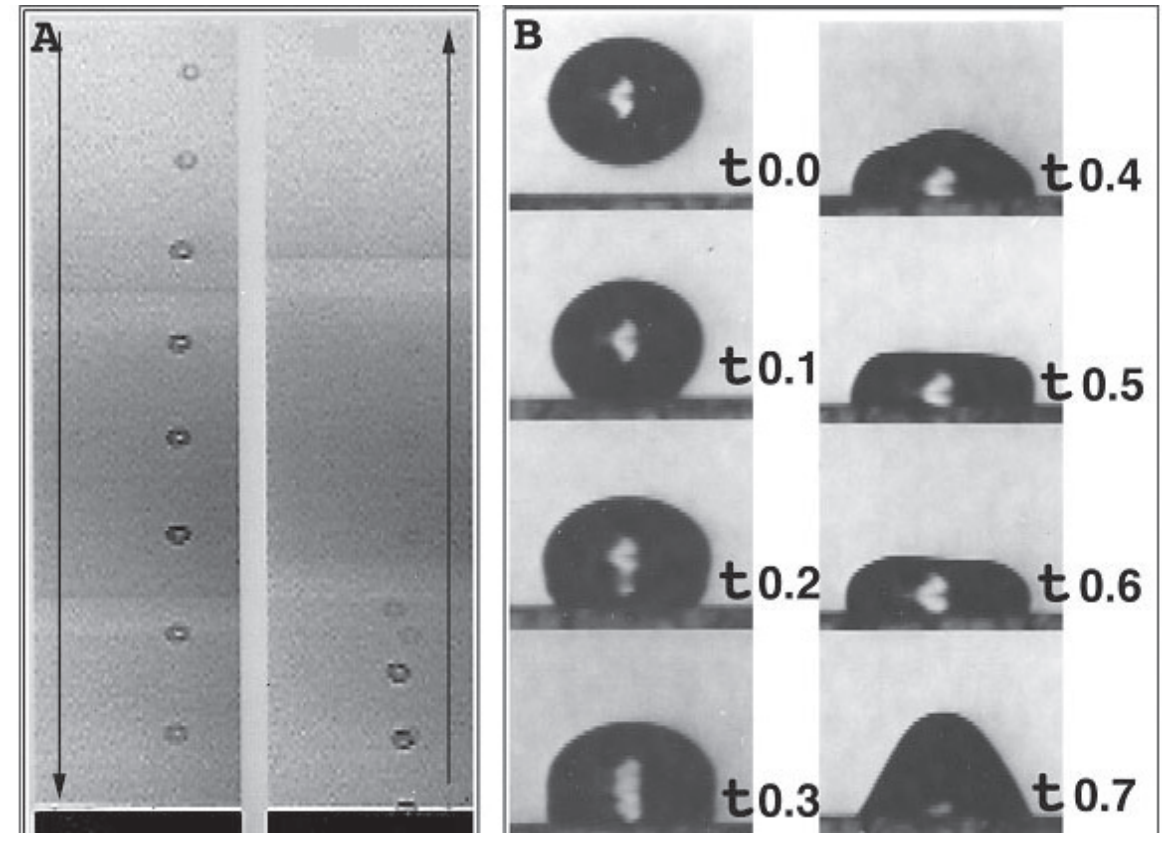

Fig. 2. Photographs taken at high speed of water droplets [330-um diameter, incoming velocity of $\left.0.65 \mathrm{~m} \cdot \mathrm{s}^{-1}(2.133 \mathrm{ft} / \mathrm{s})\right]$ impinging and reflecting (A) from a glass surface and deformation (B) of a similar droplet during the first $0.7 \mathrm{~ms}$ after contact with the surface (after Bukovac et al., 2002). 
sorption and penetration. Often the bulk of the deposit is localized as an annulus at the periphery of the droplet/air/surface interface (Fig. 3A).

Further, the a.i. residue may exist as crystalline or amorphous masses separately or, if a spray additive is present, commingled in a liquid crystal form or solubilized in the residue of the spray additive (Fig. 4). The significance of the deposition of the a.i. in a domain different from the spray additive, particularly a surfactant or spray oil, on penetration is not clear.

RELATIVE ROLE OF DROPLET AND DEPOSIT IN A.I. PENETRATION. Early studies on penetration of PGR [e.g., 2-(1-naphthyl)acetic acid (NAA) and 2-(1-naphthyl)acetamide (NAAm)], from simulated spray droplets suggested that most of the a.i. penetrated during the droplet drying phase (Greene and Bukovac, 1971; Luckwill and Lloyd-Jones, 1962), and that increased penetration under high humidity was related to the prolonged drying time (Luckwill and Lloyd-Jones, 1962). However, with incorporation of spray additives, it is clear now that the deposit may also serve as a significant donor for penetration, depending on chemistry of the a.i. and composition of the deposit (Bukovac et al., 2002; Knoche and Bukovac, 1992). Spray additives that are hygroscopic or deliquescent increase the hydration of the deposit, and the a.i. in the bulk of the deposit can more readily diffuse to the a.i.-depleted deposit: surface interface and replace the a.i. diffusing into the plant, thus maintaining a positive driving force for penetration after the droplet appears to have dried (Bukovac et al., 2003b).

\section{Spray adjuvants}

Adjuvants are defined as a variety of diverse "materials that are added to the spray tank mixture to aid or

Fig. 4 (right). Scanning electron micrograph (A) of a droplet deposit of ethephon (2-chloroethylphosphonic acid) with $0.1 \%$ Tween $80-\mathrm{Br}$ ( $\mathrm{Br}$ substituted in oleic acid side chain). $\mathrm{X}$-ray maps of deposit in A denoting the distribution of $\mathrm{Br}$ of Tween 80 (B) and $\mathrm{Cl}(\mathrm{C})$ and $\mathrm{P}(\mathrm{D})$ of ethephon. Note that distribution of the surfactant $(B)$ is not coincident with that of ethephon (B vs. C and D), much of the Tween 80- $\mathrm{Br}$ deposition occurs in different domains on the leaf surface (after Bukovac et al., 1995).

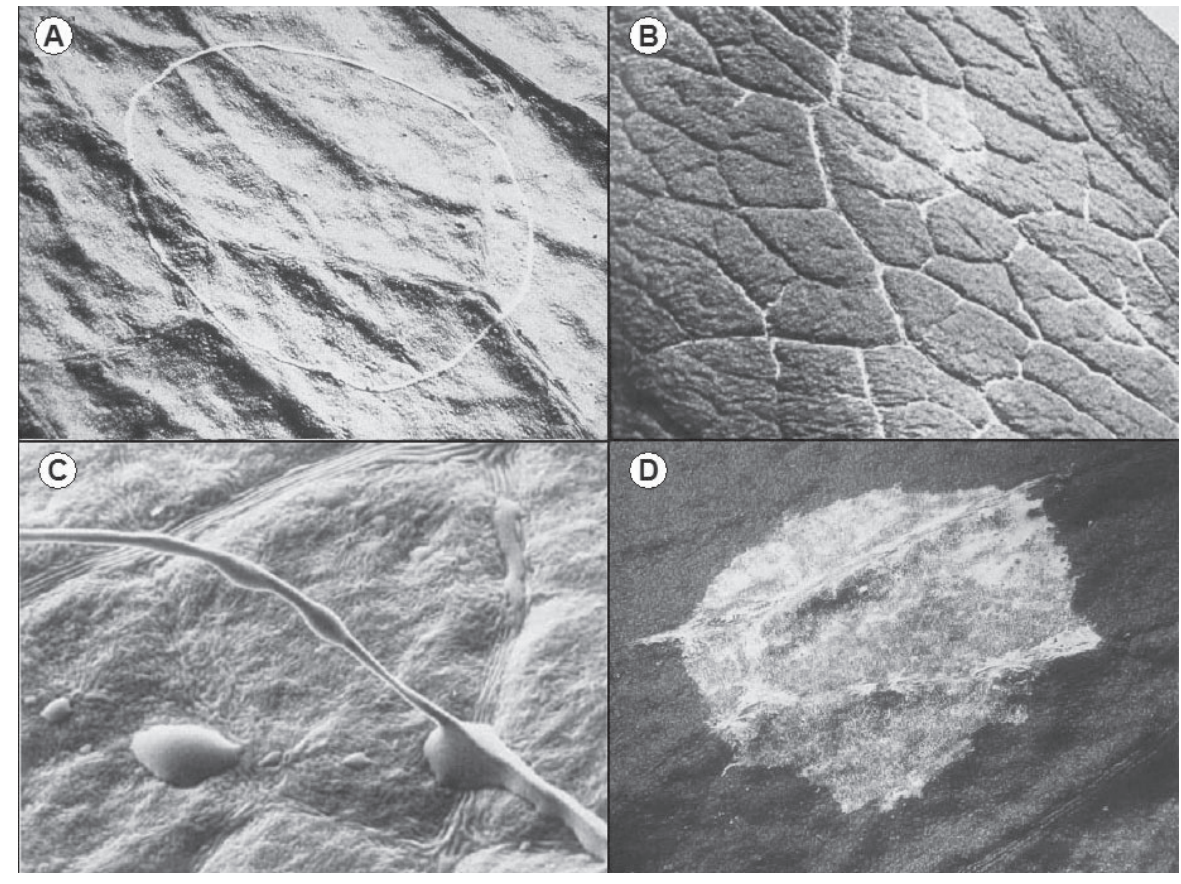

Fig. 3 (above). Scanning electron micrographs of droplet deposits (residues) illustrating different deposit forms and leaf impaction sites; 2,4,5-trichlorophenoxypropionic acid $(2,4,5-\mathrm{TP})$ on an adaxial 'Bradford' pear [Pyrus calleryana (A)] and abaxial 'Hedelfinger' sweet cherry [Prunus avium (B, C, D)] leaf surfaces. 2,4,5-TP in the form of an annulus (A), ethephon after impacting over veins (B), on a trichome (C), and from a low volume (D), $233.8 \mathrm{~L} \cdot \mathrm{ha}^{-1}(25 \mathrm{gal} / \mathrm{acre})$ spray (after Bukovac et al., 1995).
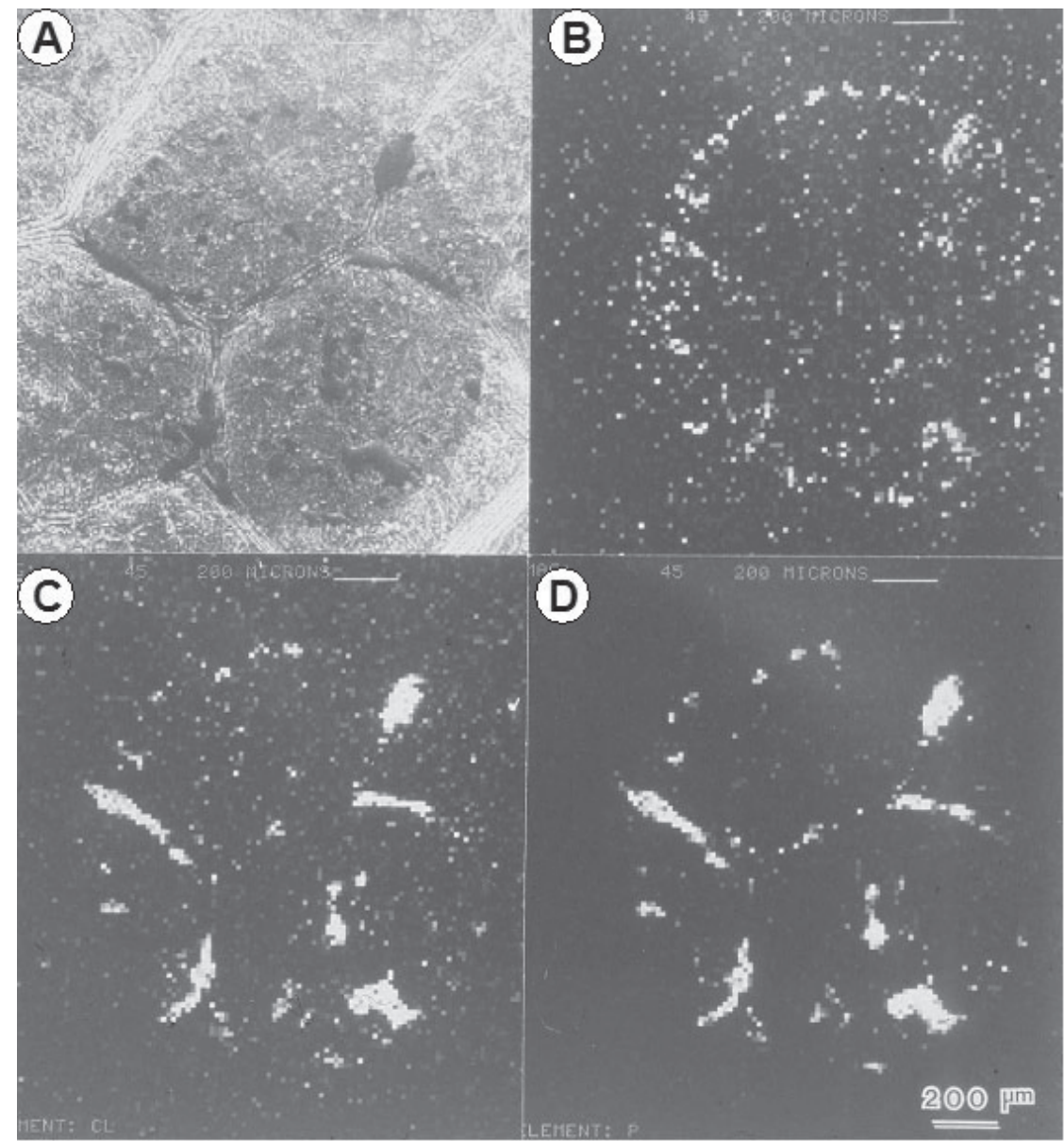

(D)

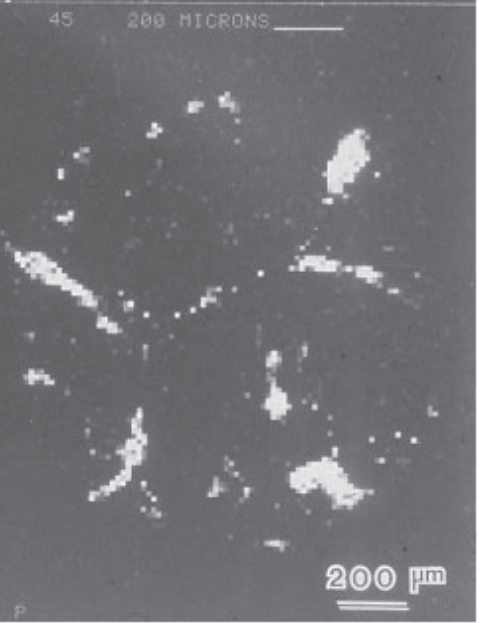


modify the action of an agrochemical, or the physical characteristics of the spray mixture." Early mention of the use of substances, now considered adjuvants, dates back to the 1800s where household items like molasses, sugar, milk, oils, natural resins, etc., were added to sprays of lime sulfur, bordeaux, and lead arsenate to improve "sticking" of the spray. Concurrent with the introduction of new, sophisticated pesticides and spray application systems an overwhelming number of adjuvants has been introduced because of little or no regulatory oversight and ease of entry into agricultural markets. This has resulted in extensive grower confusion as to their need, selection, and effectiveness.

Recently, the agrochemical industry, through its association the Chemical Producers and Distributors Association (Alexandria, Va.), and under the auspices of the Society for Testing and Materials (West Conshocken, Pa.), has developed much needed standards for product labeling claims and adjuvant terminology. I have listed in Table 1 selective terms that may be useful in PGR application. These terms are descriptive and provide insight on the many functional claims made for adjuvants. Unfortunately, data supporting many of these claims are often limited, not readily available, and difficult, if not impossible, for users to evaluate. It is not possible to address the many products/claims in this presentation. I will focus on surfactants, since: 1) they represent the largest group used (Underwood et al., 2001); 2) many are commercially available; and 3 ) they exert multiple actions (Seaman, 1980) in a spray system; and on fertilizers used as adjuvants because of early attempts to use them with NAA (Horsfall and Moore, 1961), and there is a renewed interest in their use with the growth inhibitor Apogee (BASF Corp., Research Triangle Park, N.C.).

Surfactants (derived from surface active age $\underline{n t}$ ). Surfactants are defined, in a physical chemical sense, as substances that, in low concentration, are adsorbed onto surfaces or interfaces and alter the free energies of these surfaces (Rosen, 1988). Surfactants may affect all components of the spray system, from solubilization of the a.i. in the spray solution, to penetration and transport of the a.i. in the plant. However, from the grower's perspective, the primary uses are to improve spray

Table 1. Terminology used to classify and define the multiple functions of tank mix adjuvants that may be used in spray applications of plant growth regulators (ASTM Committee E-35, 1995).

Acidifier

Activator

Antifoaming agent (defoamer)

Buffering agent

Canopy penetrating agent

Compatibility agent

Deposition aid

Drift control agent

wetting of the target surface and a.i. penetration. For a discussion of other effects, see Bukovac et al. (2003a).

All surfactants lower spray surface tension and improve wetting. The leaf surfaces of most temperate zone tree fruits are relatively easy to wet, with water/leaf contact angles $(\theta)$ of $\sim 70^{\circ}$ to $\sim 105^{\circ}$ (Bukovacetal., 1995). Thus, is it necessary to add a surfactant to improve wetting? Reducing the surface tension of a high volume spray will reduce retention, i.e., increase runoff, and drying time (Bukovac et al., 1995; Furmidge, 1962). Adding a surfactant to a low volume spray, where the spray remains as discrete droplets, will increase the droplet/leaf interface area and reduce the drying time. Surfactants in both high and low volume sprays generally increase spray retention on difficult to wet surfaces $\left(\theta>105^{\circ}\right)$.

Another important use for surfactants is to enhance a.i. penetration. While all surfactants improve wetting, not all increase penetration. To understand the effects of surfactants on penetration requires a better understanding of the multiplicity of surfactant action on the spray solution, droplet deposit, and the cuticular membrane, which is the prime barrier to penetration. Surfactants may alter the solubility of the a.i. in the spray solution, hence its sorption into the cuticle, and increase the droplet/surface contact. They may increase, have no effect, or reduce a.i. penetration through the cuticular membrane (Schönherr et al., 2000; Shafer et al., 1989). The exact mechanisms are not clear, but the following modes of action are supported by recent studies (Schönherr, 1993; Schönherr et al., 1999). Surfactants can be assigned to three general classes based on their penetration of the cuticle. They can be sorbed and penetrate the cuticle at varying rates, primarily based on their polarity. The less polar surfactants

\section{Emulsifier}

Evaporation reduction agent

Extender

Humectant

Penetrant

Spreader/wetting agents

Sticker

Surface active agent (surfactant)

plasticize the cuticular waxes, making them a less significant barrier to penetration (Baur, 1998). For a surfactant to enhance penetration of an a.i., both must penetrate to the wax barrier at about the same rate; the surfactant then plasticizes the wax, facilitating penetration of the a.i. (Schönherr and Baur, 1994). If the surfactant penetrates at a slower or faster rate than the a.i., the two may not arrive at the wax barrier at the same time and penetration will not be enhanced. Some surfactants [Tween 20 (Sigma Aldrich, St. Louis, Mo.); Regulaid (Kalo Inc., Overland Park, Kans.)] do not penetrate rapidly and, on droplet drying, are deposited as an amorphous mass, gel, or liquid crystal. Chemistry of the a.i. will influence whether it has greater affinity for the surfactant residue or the cuticle. If the a.i. is sorbed by the surfactant residue, it is not readily available for penetration. This effect can be dramatically illustrated by reduced phytotoxicity on leaves of cowpea (Vigna unguiculata), cotton (Gossypium bardadense), or bean (Phaseolus vulgaris) plants when droplets with a phytotoxic dose of NAA are applied with increasing concentrations of Triton X-405 surfactant (Rohm and Haas, Philadelphia) with a long oxyethylene chain (40 units), representing increasing polarity and film-forming properties (W.E. Shafer, unpublished data).

Surfactants in a droplet residue may facilitate continued penetration of the a.i. from the deposit by absorbing water from the air and maintaining the deposit in a hydrated state. This condition would favor diffusion of the a.i. from the deposit bulk to the leaf interface, replenishing the a.i. penetrating into the leaf, and maintaining the driving force for diffusion into the cuticle (Bukovac et al., 2002). Thus, surfactants may enhance penetration from both the droplet aqueous and residue phases. 
Some surfactants may enhance wetting and penetration by deforming the fine structure of the epicuticular wax (Bukovac et al., 1986; Kuzych and Meggit, 1983) and by solubilizing wax constituents (Tamura et al., 2001a, $200 \mathrm{lb}$ ). The former would be expected to increase wetting and sorption and the latter to increase the permeability of the cuticular membrane.

With introduction of organosilicone chemistry-based surfactants and blends capable of reducing surface tension to less than $25 \mathrm{mN} \cdot \mathrm{m}^{-1}$, mass flow of the spray solution through stomatal pores becomes an additional method of enhancing a.i. penetration (Knoche, 1994b; Stevens et al., 1991). These findings are in contrast to earlier studies with most nonionic, agricultural surfactants that did not reduce surface tension sufficiently to induce stomatal penetration because of the unique morphology (i.e., wall angles) of the stomatal ledges (Green and Bukovac, 1977; Jyung et al., 1965; Schönherr and Bukovac, 1972).

\section{Fertilizers as adjuvants}

Liquid fertilizer formulations were shown to enhance activity of growth regulator type herbicides over 30 years ago (Linder, 1973). Subsequent studies have provided the basis for commercial application of urea, ammonium nitrate and sulfate, and a widely used mixture of urea plus ammonium nitrate, for weed control in agronomic crops (Sprague et al., 2004). Although extensive studies have been performed, no one suggested mode of action has emerged as an explanation, but rather each may have some merit for a specific a.i. and plant combination. Hypotheses proposed include: 1) improved spray water quality by complexing competing ions, especially calcium; 2) direct reaction with the a.i.; 3) suppression of dissociation of the a.i. by an "ionic strength effect"; 4) negating the repulsive interactions between the a.i. and the cuticle; and 5 ) effects on cell metabolism and cell membranes (deRuiter et al., 1994; Gronwald et al., 1993; Schönherr et al., 2000; Thelen et al., 1995).

Interestingly, some of the earliest observations of urea and/or ammonium nitrate on enhancing performance of foliar-applied minor elements and growth regulators were made with horticultural crops. Incorporating urea in sprays of minor elements was widely practiced in the Hawaiian pineapple (Ananascomosus) industry in the 1950 s (Wittwer and Teubner, 1959). Horsfall, using NAA for apple fruit thinning in Virginia, performed extensive studies using urea, ammonium nitrate and other nitrogen-containing compounds as adjuvants, but no significant commercial application emerged (Horsfall and Moore, 1961). The first significant use of a fertilizer adjuvant, ammonium sulfate, for a PGR on horticultural crops was in the late 1990s in conjunction with the development of the growth inhibitor prohexadione-calcium, Apogee (Byers, 2004).

Horsfall and Moore (1961) found an enhancement of NAA activity when urea, ammonium nitrate and several other nitrogen containing compounds were added to the spray, but the results were inconsistent, weather related and difficult to reproduce. As a young faculty member I had several discussions with Dr. Horsfall and he consistently encouraged me and others to pursue his observations. I performed limited experiments on several occasions and similar variable responses were observed, namely, 1) increased epinasty induced by 2,3,5-triiodobenzoic acid (TIBA) for flower promotion in 'Delicious' apple; and 2) several instances of increased thinning with NAA in grower trials.

Recently we initiated studies in an attempt to clarify the role of urea and ammonium nitrate (AMN) on cuticular penetration of NAA from defined simulated spray droplets through isolated astomatous tomato (Lycopersicon esculentum) fruit cuticles. We utilized a finite dose diffusion system (Fig. 5A) because it provided for 1) a defined spray solution, composition and $\mathrm{pH} ; 2$ ) a critical measurement of the maximum rate of penetration and the amount of ${ }^{14} \mathrm{C}$-NAA penetrating over a prescribed time, usually 120 h; 3 ) the ability to observe and relate penetration from the droplet liquid (during drying) and residue phases; 4) use of defined temperature and relative humidity $(\mathrm{RH}) ; 5)$ a physical system (isolated cuticle, no living tissue present) representing the primary barrier to penetration; and 6) the opportunity to separate AMN effect on a.i./spray solution from direct effect on the cuticle.

The treatment effects on NAA penetration were measured by analyzing the maximum rate $\left(\mathrm{R}_{\max }\right)$ of penetration, calculated by regression of four data points $(4,6,9,12 \mathrm{~h})$ on the near linear phase of the time course curve, and the total amount of NAA penetrated after $120 \mathrm{~h}\left[\left(\mathrm{P}_{120}\right)\right.$ (Bukovac and Petracek, 1993)].

We found that urea alone did not consistently increase NAA penetration, whereas AMN increased NAA penetration $\left(\mathrm{P}_{120}\right) 3$ - to 4 -fold over a broad concentration ( 1 to $125 \mathrm{~mm}$ ) range.

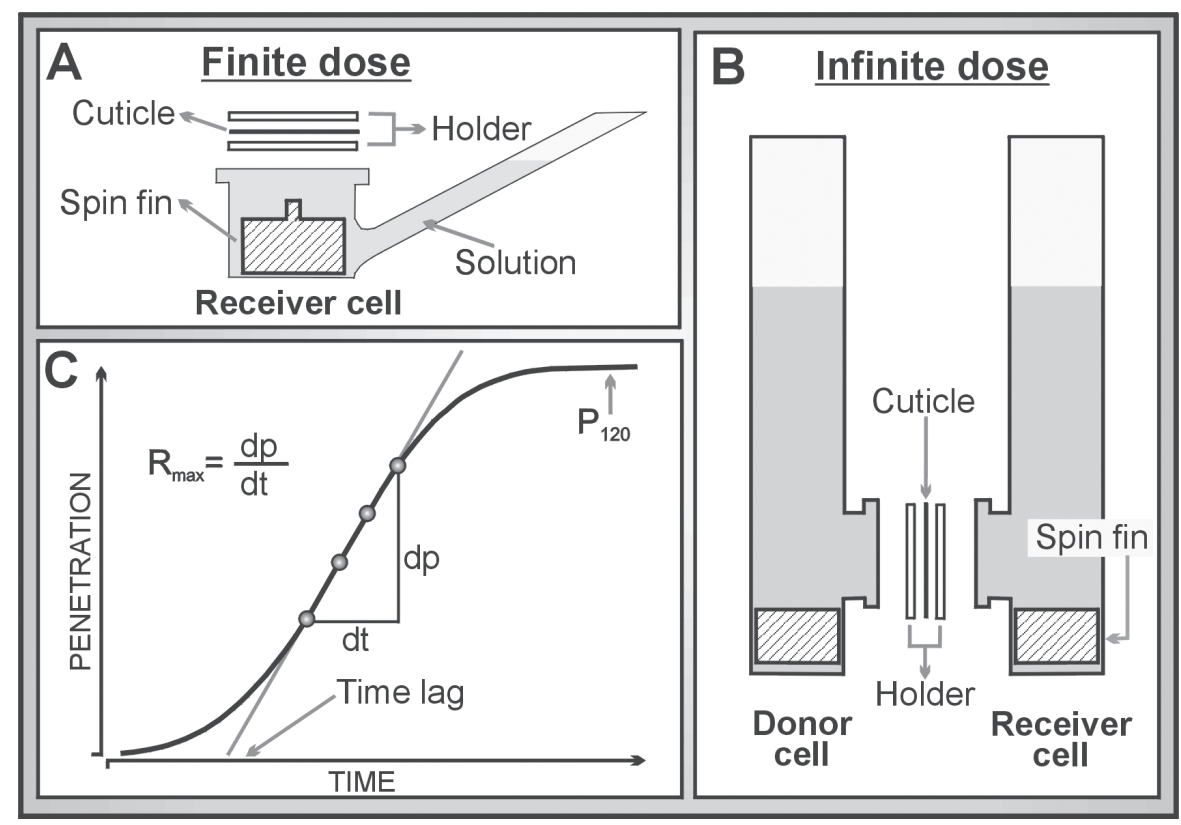

Fig. 5. Diagram of finite (A) and infinite (B) dose diffusion cells and plot of typical time course data $(C)$ used to calculate the maximum rate $\left(R_{\max }\right)$ of diffusion and the amount penetrating in a specified time interval $\left(\mathrm{P}_{\text {time }}\right)$. 
The AMN response was $\mathrm{pH}$ dependent, increasing NAA penetration in the anion form ( $\mathrm{pH} 5.2$ ) by $~ 3$-fold $\left(\mathrm{P}_{120}\right)$, but only by $\sim 13 \%\left(\mathrm{P}_{120} 371\right.$ vs. 329$)$ at $\mathrm{pH}$ 3.2 (nondissociated form). The NAA time course penetration curve at $\mathrm{pH}$ 5.2 plus $\mathrm{AMN}$ was almost identical to that at $\mathrm{pH} 3.2$ in the absence of AMN. This is significant, because NAA, as well as other weak organic acids, penetrates into leaves (cuticles) more readily as the nondissociated than as the dissociated moiety (Crafts, 1961; Norris and Bukovac, 1971). Thus, AMN appears to increase NAA anion penetration to rates similar to that of the nondissociated molecule. In practice, the addition of ammonium nitrate to NAA in an alkaline spray solution ( $\mathrm{pH}$ above the NAA pK, 4.2) may overcome a high $\mathrm{pH}$ water quality limitation and improve penetration.

Ammonium nitrate consistently increased NAA penetration, measured by both the $\mathrm{R}_{\max }$ and $\mathrm{P}_{120}$, over a broad range in $\mathrm{RH}$. The percentage enhancement was greater at a RH below than above the AMN deliquescent point $(63.8 \% \mathrm{RH})$. This observation also has practical implications. Ammonium nitrate would be expected to overcome low RH limitations at time of treatment, and have only a minimal effect under high $\mathrm{RH}$, thus tend to improve performance under unfavorable, but have little or no effect under favorable $\mathrm{RH}$ conditions. This is consistent with the field observations and supports the conclusion of Horsfall and Moore (1961). Similar enhancement of biological activity of NAA and 2,4-D in auxin-induced ethylene formation, of AVG $\{[S]$-trans-2-amino-4-(2-amino ethoxy)-3-butenoic acid $\}$ for inhibiting ethylene synthesis (Ogata et al., 2001) and of $\mathrm{GA}_{3}$ in promoting grape (Vitis vinifera) berry growth (Ungsa et al., 2003 ) has been observed.

Related ammonium sulfate and phosphate salts induced similar enhancement of NAA penetration, but potassium and calcium nitrate depressed penetration by $\sim 24 \%$ and $~ 60 \%$, respectively. The alkylamines, methyl, ethyl, and propyl, also increased NAA penetration (Bukovac et al., 2003b).

Three additional observations from this study need to be noted before addressing the possible mechanisms of AMN action. First, the AMN must be present with the NAA in the spray solution. If NAA is supplied alone in the donor droplet and AMN is placed only in the receiver cell solution (Fig. $5 \mathrm{~A}$ ), no enhancement of NAA penetration is observed. Likewise, if the isolated cuticle is permitted to sorb (equilibrate) AMN prior to NAA application, there is no effect on NAA penetration, suggesting no direct effect on cuticular permeability. Second, progressively increasing the AMN concentration 31 -fold in the donor cell with NAA in an infinite dose diffusion system (Fig. 5B), i.e., NAA diffusion from an aqueous donor through the cuticle to an aqueous receiver (no donor drying), does not enhance NAA penetration. This provides evidence that the AMN effect requires droplet (donor) drying, and is indirect proof that increasing the concentration (increasing ionic strength) of AMN does not in itself protonate the NAA, and is further evidence that the AMN does not alter cuticular permeability. Third, the AMN has a dramatic effect on the physical form of the droplet residue. Droplets of NAA solutions dried to a crystalline residue in 15 to 30 min. With AMN, similar droplets dried to an amorphous mass within $30 \mathrm{~min}$ at low $\mathrm{RH}$, but only dried down to a viscous liquid or gel above $65 \%$ RH (Fig. 6). On transfer to low $\mathrm{RH}(<50 \%)$, the residue now dried to an amorphous mass. We determined the deliquescent point to be $63.8 \%$ $\mathrm{RH}$. Thus, by changing the RH, the physical form was readily manipulated. Such physical changes in the deposit may affect the donor properties of the residue and can be expected to occur under field conditions.

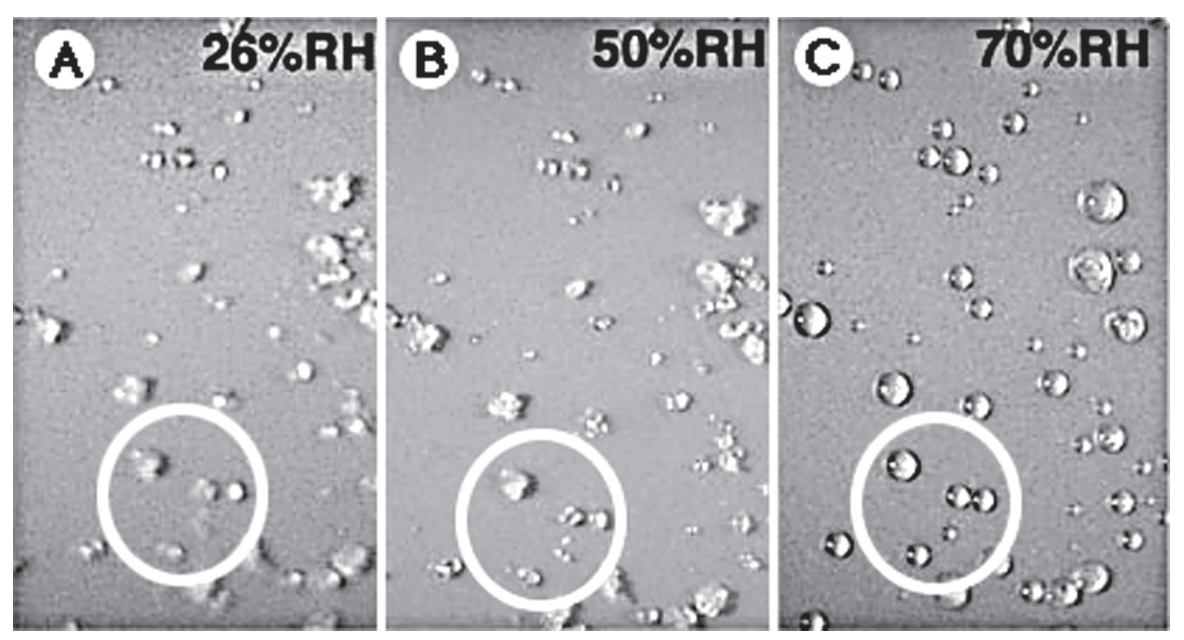

Fig. 6. Photographs of ammonium nitrate crystals on isolated tomato fruit cuticular membranes at relative humidity below $(\mathrm{A}, \mathrm{B})$ and above $(\mathrm{C})$ the deliquescent point $[62.8 \%$ relative humidity $(\mathrm{RH})]$. Note change from a crystal state below $(A, B)$ to a liquid above $(C)$ the deliquescent point (after Bukovac et al., 2002). 
did not support this conclusion. The addition of the adjuvant is sufficiently critical to Apogee performance that the manufacturer has incorporated AMS $(-56 \%)$ in the formulation of the a.i. in the commercial product. Further, for use on apples, additional ammonium sulfate (1 kg AMS per $1 \mathrm{~kg}$ Apogee) is recommended in the label if the spray water has a high level of calcium carbonate (BASF, 2004). To my knowledge, this is the first PGR for use by the U.S. fruit industry where a fertilizer adjuvant has been incorporated in the product formulation. Thus, the role of the fertilizer class of adjuvants in PGR performance has taken on a new dimension.

\section{Literature cited}

ASTM Committee E-35. 1995. Standard terminology relating to pesticides: Tank mix adjuvants. Designation E-1519-95. Ann. Book ASTM Standards. Amer. Soc. Testing and Materials. ASTM Intl., Philadelphia.

BASF. 2004. Apogee. BASF Corp., Research Triangle Park, N.C.

Baur, P. 1998. Mechanistic aspects of foliar penetration of agrochemicals and the effects of adjuvants. Recent Res. Agr. Food Chem. 3:809-837.

Brunskill, R.T. 1956. Physical factors affecting the retention of spray droplets on leaf surfaces. Proc. Third Weed Cont. Conf. 2:593-603.

Bukovac, M.J., J.A. Cooper, R.E. Whitmoyer, and R.D. Brazee. 2002. Spray application plays a determining role in performance of systemic compounds applied to the foliage of fruit plants. Acta Hort. 594:65-75.

Bukovac, M.J., J.A. Cooper, R.E. Whitmoyer, and R.D. Brazee. 2003a. Pesticide delivery: Multiple role of adjuvants in foliar application of systemic compounds, p. 91-107. In: R.A. Downer, J.C. Mueninghoff, and G.C. Volgas (eds.). Pesticide formulations and delivery systems: Meeting the challenges of the current crop protection industry. ASTM STP 1430. ASTM Intl., West Conshocken, Pa.

Bukovac, M.J., R.G. Fader, and P. Luque. 2003b. Effects of urea and ammonium nitrate on penetration of NAA through enzymatically isolated tomato fruit cuticular membranes, p. 15-31. In: G. Volgas, R. Downer, and H. Lopez (eds.). Pesticide formulations and application systems. 23rd Intl. Symp. ASTM Intl., West Conshocken, Pa.

Bukovac, M.J., J.A. Flore, and E.A. Baker. 1979. Peach leaf surfaces: Changes in wettability, retention, cuticular permeability, and epicuticular wax chemistry during expansion with special reference to spray application. J. Amer. Soc. Hort. Sci. 104:611-617.

Bukovac, M.J., J.M. Leon, J.A. Cooper, R.E. Whitmoyer, D.L. Reichard, and R.D. Brazee. 1995. Spray droplet: Plant surface interaction and deposit formation as related to surfactants and spray volume, p. 177-185. In: R.E. Gaskin (ed.). 4th Intl. Symp. on Adjuvants for Agr. FRI Bul. 193. N.Z. For. Res. Inst. Ltd., Rotorua.

Bukovac, M.J. and P.D. Petracek. 1993. Characterizing pesticide and surfactant penetration with isolated plant cuticles. Pesticide Sci. 37:179-194.

Bukovac, M.J., D.L. Reichard, and R.E. Whitmoyer. 1986. The spray application process: Central for the efficient use of growth regulators in tree fruits. Acta Hort. 179:(1)33-45.

Butler, E., C.R. Tuck, and P.C.H. Miller. 1997. The effect of some adjuvants on sprays produced by agricultural flat fan nozzles. Crop Protection 16:41-50.

Byers, R.E. 2004. Prohexadione-calcium suppression of apple tree shoot growth affected by spray additives. HortScience 39:115-119.

Byers, R.E., K.D. Hickey, and C.H. Hill. 1971. Base gallonage per acre. Virginia Fruit 60:19-23.

Byers, R.E., H.W. Hogmire, D.C. Ferree, F.R. Hall, and S.J. Donahue. 1989. Spray chemical deposits in high-density and trellis apple orchards. HortScience 24:918-920.

Byers, R.E., G.G. Lyons Jr., K.S. Yoder, R.L. Horsburg, J.A. Barden, and S.J. Donohue. 1984. Effect of apple tree size and canopy density on spray chemical deposit. HortScience 19:93-94.

Crafts, A.S. 1961. Improvement of growth regulator formulation, p. 789-802. In: Plant growth regulation. Iowa State Univ. Press, Ames.

Cross, J.V., P.J. Walklate, R.A. Murray, and G.M. Richardson. 2001. Spray deposits and losses in different sized apple trees from an axial fan orchard sprayer: 1. Effects of spray liquid flow rate. Crop Protection 20:13-30.

deRuiter, H., M.A.M. Verbeek, and A.J.M. Uffing. 1994. Influence of ammonium sulfate and two surfactants on the phytotoxicity and uptake of glyphosate. Mededelingen Faculteit Landbounweten Schappen, University of Gent. 59:1403-1408.

Falk, R.H. 1994. Influence of formulation and adjuvants on the foliar location and physical form of the active ingredient, $\mathrm{p}$. 53-82. In: P.J. Holloway, R. Rees, and D. Stock (eds.). Interactions between adjuvants, agrochemicals and target organisms. Springer Verlag, Berlin.

Furmidge, C.G.L. 1962. Physico-chemical studies on agricultural sprays. IV. The retention of spray liquids on leaf surfaces. J. Sci. Food Agr. 13:127-140.

Greene, D.W. and M.J. Bukovac. 1971. Factors influencing the penetration of naphthaleneacetamide into leaves of pear (Pyrus communis L). J. Amer. Soc. Hort. Sci. 96:240-246.

Greene, D.W. and M.J. Bukovac. 1977. Foliar penetration of naphthaleneacetic acid: Enhancement by light and role of stomata. Amer. J. Bot. 64:96-101.

Gronwald, J.W., S.W. Jourdan, D.L. Wyse, D.A. Somers, and M.U. Magnusson. 1993. Effect of ammonium sulfate on absorption of imazethapyr by quackgrass (Elytrigia repens) and maize (Zea mays) cell suspension cultures. Weed Sci. 41:325-334.

Hall, F.R., R.A. Downer, J.A. Cooper, T.A. Ebert, and D.C. Ferree. 1997. Changes in spray retention by apple leaves during a growing season. HortScience 32:858-860.

Hartley, G.S. and R.T. Burnskill. 1958. Reflection of water drops from surfaces, p. 214-223. In: J.F. Danielli, K.G.A. Pankhurst, and A.C. Reddiford (eds.). Surface phenomena in chemistry and biology. Pergamon Press, London.

Hartley, G.S. and I.J. Graham-Bryce. 1980. Physical principles of pesticide behavior. Academic Press, London.

Hogmire, H.W., R.G. Diener, and V.L. Crim. 1991. Comparison of boom and airblast sprayers on T-trellis apples. J. Agr. Sci. 116:253-257.

Hogmire, H.W., M.J.Wimmer, V.L. Crim, R.M. Welker, E. Wentz, and R.R. Smith. 1992. Influence of tree growth on spray chemical deposits on peach leaves. J. Agr. Sci. 118:77-81.

Horsfall, Jr., F., and R.C. Moore. 1961. New chemical potentiates and weather as adjuvants to apple thinning by the sodium salt of naphthaleneacetic acid. Proc. Amer. Soc. Hort. Sci. 77:9-21.

Jyung, W.H., S.H. Wittwer, and M.J. Bukovac. 1965. The role of stomata in the foliar absorption of Rb by leaves of tobacco, bean and tomato. Proc. Amer. Soc. Hort. Sci. 86:361-367.

Kaul, P., K. Schmidt, and H. Koch. 1996. Distribution quality of orchard sprayers, Bul. European Plant Protection Org., OEPP/EPPO Bul. 26. 
Knoche, M. 1994a. Effect of droplet size and carrier volume on performance of foliage-applied herbicides. Crop Protection 13:163-178

Knoche, M. 1994b. Organosilicone surfactant performance in agricultural spray application: A review. Weed Res. 34:221-239.

Knoche, M. and M.J. Bukovac. 1992 Surfactants influence foliar absorption of gibberellic acid by sour cherry leaves. J. Amer. Soc. Hort. Sci. 117:80-84.

Knoche, M., N.K. Lownds, and M.J. Bukovac. 2000. Spray application factors and plant growth regulator performance: IV. Dose response relationships. J. Amer. Soc. Hort. Sci. 125:195-199.

Kuzych, I.J. and W.F. Megitt. 1983. Alteration of epicuticular wax structure by surfactants. Micron Microscopica Acta. $14: 279-280$

Linder, P. 1973. Agricultural formulations with liquid fertilizers, p. 113-141. In: W. van Valkenburg (ed.). Pesticide formulations. Marcel Dekker, New York.

Luckwill, L.C. and C.P. Lloyd-Jones. 1962. The absorption, translocation and metabolism of 1-naphthaleneacetic acid applied to apple leaves. J. Hort. Sci. 37:190-206.

Matthews, G.A. 1999. Application of pesticides to crops. Imperial College Press, London.

Morgan, N.G. 1964. Gallons per acre of sprayed area: An alternative standard term for spraying plantations. World Crops 16:64-65.

Norris, R.F. and M.J. Bukovac. 1971. Effect of $\mathrm{pH}$ on penetration of naphthaleneacetic acid through isolated pear leaf cuticle. Plant Physiol. 49:615-618.

Ogata, T., M. Taketomi, S. Shiozaki, R.G. Fader, and M.J. Bukovac. 2001. Ammonium nitrate enhances plant growth regulator performance. Acta Hort. p. 120-121. (Extended Abstr.)

Randall, J.M. 1971. The relationships between air volume and pressure on spray distribution in fruit trees. J. Agr. Eng. Res. 16:1-31.

Ranz, W.E. 1956. On sprays and spraying. Engr. Res. Bul. B-65. Pennsylvania State Univ., University Park.

Reichard, D.L., J.A. Cooper, M.J. Bukovac, and R.D. Fox. 1998. Using a videographic system to assess spray droplet impaction and reflection from leaf and artificial surfaces. Pesticide Sci. 53:291-299.

Reichard, D.L., H.J. Retzer, L.A. Liljedahl, and F.R. Hall. 1977. Spray droplet size distributions delivered by air-blast orchard sprayers. Trans. Amer. Soc. Agr. Eng. 20:232-237, 242 .

Rosen, M.J. 1988. Surfactants and interfacial phenomena, 2nd ed. Wiley, New York.

Schönherr, J. 1976. Naphthaleneacetic acid permeability of citrus leaf cuticle. Biochem. Physiol. Pflanzen 170:309-319.

Schönherr, J. 1993. Effects of monodisperse alcohol ethoxylates on mobility of 2,4-D in isolated cuticles. Pesticide Sci. 38:155-164.

Schönherr, J. and P. Baur. 1994. Modelling penetration of plant cuticles by crop protection agents and effects of adjuvants on their rates of penetration. Pesticide Sci. 42:185-208

Schönherr, J., P. Baur, and A. Bucholz. 1999. Modelling foliar penetration: Its role in optimizing pesticide delivery, $\mathrm{p}$. 134-151. In: Pesticide chemistry and the bioscience. The food-environment challenge. Royal Soc. Chem., London.

Schönherr, J., P. Baur, and B.A. Uhlig. 2000. Rates of cuticular penetration of 1 naphthaleneacetic acid (NAA) as affected by adjuvants, temperature, humidity and water quality. Plant Growth Regulat. 31:61-74.

Schönherr, J. and M.J. Bukovac. 1972. Penetration of stomata by liquids: Dependence on surface tension, wettability and stomatal morphology. Plant Physiol 49:813-819.

Seaman, D. 1980. Pesticide surfactant systems. A multiplicity of surfactant physical properties employed to improve the biological effect, p. 1365-1380. In: K.L. Mittal and E.J. Fendler (eds.). Solution behavior of surfactants. Theoretical and applied aspects. Vol. 2. Plenum Press, New York.

Shafer, W.E., M.J. Bukovac, and R.G. Fader. 1989. Studies on octylphenoxy surfactants. IV. Their sorption and effects on NAA partitioning into plant cuticles, p. 39-49. In: P. Chow, C. Grant, A.M. Hinshalwood, and E. Simundsson (eds.). Adjuvants and agrochemicals, Vol. II. Recent development, application, and bibliography of agro-adjuvants. CRC Press, Boca Raton, Fla.

Spillman, J.J. 1984. Spray impaction, retention and adhesion: An introduction to basic characteristics. Pesticide Sci. 15:97-106.

Sprague, C.L., J.J. Kells, and K. Schirmacher. 2004. Weed control guide for field crops. Ext. Bul. E-434, Michigan State Univ., East Lansing.

Stevens, P.J.G. and M.J. Bukovac. 1987. Effects of spray application parameters on foliar uptake and translocation of damino- zide and 2,4-D-triethanolamine in Vicia faba. Crop Protection 6:163-170.

Stevens, P.J.G., R.E. Gaskin, S.O. Hong, and J.A. Zabkiewicz. 1991. Contributions of stomatal infiltration and cuticular penetration to enhancements of foliar uptake by surfactants. Pesticide Sci. 33:371-382.

Sutton, T.B. and C.R. Unrath. 1984. Evaluation of the tree-row-volume concept with density adjustments in relation to spray deposits in apple orchards. Plant Dis. 68:480-484.

Tamura, H., M. Knoche, and M.J. Bukovac. 200la. Evidence for surfactant solubilization of plant epicuticular wax. J. Agr. Food Chem. 49:1809-1816.

Tamura, H., M. Knoche, and M.J. Bukovac. 2001b. Selective solubilization of tomato fruit epicuticular wax constituents by Triton X-100 surfactant. J. Pesticide Sci. 26:16-20.

Thelen, K.D., E.P. Jackson, and D. Penner. 1995. The basis for the hard-water antogonism of glyphosate activity. Weed Sci. $43: 541-548$.

Travis, J.W., W.A. Skroch, and T.B. Sutton. 1987. Effect of canopy density on pesticide deposition and distribution in apple trees. Plant Dis. 71:613-615.

Underwood, A., S. Roberts, and F. Yopp. 2001. An overview of the commercial, agrochemical, and adjuvant market trends impacting each for the 21 st century. $p$. 608-620. In: H. deRuiter (ed.). 6th Intl. Symp. Adjuvants Agr., Amsterdam, The Netherlands.

Ungsa, M., K. Kato, K. Takemura, T. Hori, H. Ohara, K. Ohkawa, H. Matsui, and M.J. Bukovac. 2003. Effects of the combination of gibberellic acid and ammonium nitrate on the growth and quality of seedless berries in 'Deleware' grape. J. Jpn. Soc. Hort. Sci. 72:366-371.

Walklate, P.L., J.V. Cross, G.M. Richardson, R.A. Murray, and D.E. Baker. 2002. Comparison of different spray volume deposition models using LIDAR measurements of apple orchards. Biosystems Eng. $82: 253-267$

Wirth, W., S. Strop, and W. Jacobsen. 1991. Mechanisms controlling leaf retention of agricultural spray solutions. Pesticide Sci. 33:411-420.

Wise, J.C., L.J. Gut, R. Isaacs, A.M.C. Schilder, B. Zandstra, E. Hansen, and B. Shane. 2004. Fruit management guide for commercial fruit growers. Ext. Bul. E-154. Mich. State Univ., East Lansing.

Wittwer, S.H. and F.G. Teubner. 1959 Foliar absorption of mineral nutrients. Ann. Rev. Plant Physiol. 10:13-32. 